\title{
Workshop Penguatan Pendidikan Karakter bagi Guru Bimbingan dan Konseling SMP
}

\author{
Workshop on Strengthening Character Education for Junior High School Guidance and \\ Counseling Teachers
}

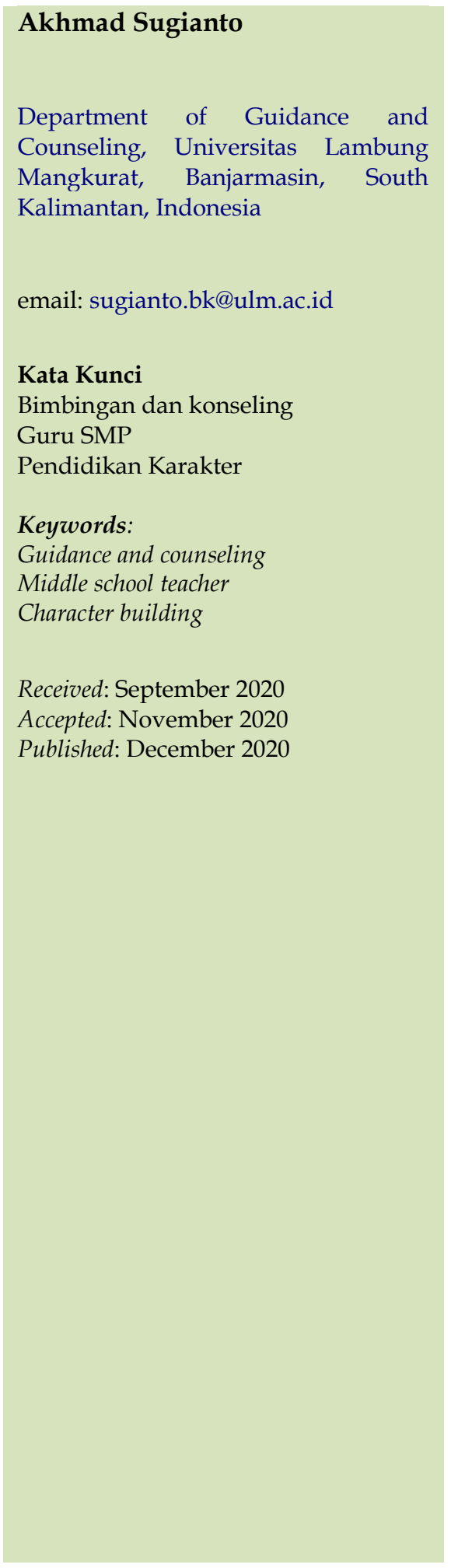

\begin{abstract}
Abstrak
Workshop Bimbingan dan Konseling Penguatan Pendidikan Karakter Dalam Pelayanan Bimbingan dan Konseling bagi Bagi Guru Bimbingan dan Konseling Sekeloh Menengah Pertama Se-Kabupaten Tabalong dilakukan dengan tujuan menyiapkan guru bimbingan dan konseling yang mampu dalam menerapkan layanan bimbingan an konseling dalam penguatan pendidikan karakter berbasis operasional penyelenggaraan bimbingan dan konseling di sekolah, sesuai dengan Pedoman Bimbingan dan Konseling pada Pendidikan Dasar dan Pendidikan Menengah yang dikeluarkan Kementerian Pendidikan dan Kebudayaan. Kegiatan workshop dilaksanakan sehari yakni pada tanggal 26 Agustus 2019, dengan jumlah peserta sosialiasasi 37 orang. Secara teknis pelaksanaan workshop berlangsung dalam 5 tahapan kegiatan yakni registrasi; ceramah; sharing pengalaman; dan tanya-jawab Praktikum. Narasumber kegiatan workshop yakni dari kalangan dosen program studi bimbingan dan konseling. Berdasarkan pelaksanaan pengabdian ini dapat disimpulkan bahwa guru bimbingan dan konseling memiliki peran penting dalam penguatan pendidikan karakter dengan menggunakan layanan bimbingan dan konseling yang berbasis Panduan Operasional Penyelenggaraan Bimbingan dan Konseling. Oleh karena itu, disarankan untuk ditindaklanjuti menjadi kegiatan bimtek dalam implementasi layanan bimbingan dan konseling dengan agenda materi kegiatan yang lebih spesifik; dan menjadi studi awal dalam pembuatan modul layanan bimbingan dan konseling untuk penguatan pendidikan karakter berbasis Panduan Operasional Penyelenggaraan Bimbingan dan Konseling.
\end{abstract}

\begin{abstract}
Guidance and Counseling Workshop on Strengthening Character Education in Guidance and Counseling Services for Junior Secondary Guidance and Counseling Teachers in Tabalong Regency was carried out to prepare guidance and counseling teachers who were capable of implementing guidance and counseling services in strengthening character education based on operational guidance and counseling in schools, by the Guidance and Counseling Guidelines for Primary and Secondary Education issued by the Ministry of Education and Culture. The workshop was held one day, namely on August 26, 2019, with 37 participants. Technically, the implementation of the workshop takes place in 5 stages of activities, namely registration; lectures; sharing experiences; and questions and answers practicum. Resource persons for the workshop activities were lecturers in the guidance and counseling study program. Based on the implementation of this service, it can be concluded that guidance and counseling teachers have an essential role in strengthening character education by using guidance and counseling services based on the Operational Guidance and Counseling Implementation Guidelines. Therefore, it is suggested to be followed up into technical guidance activities in implementing guidance and counseling services with a more specific activity agenda; and become a preliminary study in making guidance and counseling service modules for strengthening character education based on Operational Guidance for Guidance and Counseling Implementation.
\end{abstract}




\section{PENDAHULUAN}

Di era teknologi saat ini memunculkan berbagai tatanan baru, ukuran-ukuran baru, dan kebutuhan-kebutuhan baru yang berbeda dengan sebelumnya. Hal tersebut menimbulkan konsekuensi tantangan baru dalam pendidikan termasuk pendidikan nasional (Susilo \& Sarkowi, 2018). Selain itu berbagai persoalan moral, budi pekerti, watak atau karakter seperti: meningkatnya dekandensi moral, meningkatnya ketidakjujuran pelajar, dan masih tingginya kasus tindakan kekerasan yang terjadi antar pelajar seperti klitih dan tawuran serta berbagai fenomena lain yang menunjukan bahwa Indonesia telah mengalami krisis moral (Pratama, 2018). Berbagai fakta di lapangan menunjukan masih tingginya penyimpangan karakter yang dilakukan oleh generasi bangsa. Kasus IPDN misalnya, diperkirakan sebesar 89,5\% praja IPDN mengalami kasus penyiksaan dan diantaranya terdapat 16 orang meninggal (Jalal, 2010). Fenomena lain yang melanda siswa remaja bahwa sekitar 6-20\% siswa SMA dan mahasiswa di Jakarta pernah melakukan hubungan seks pra nikah. Selain itu hasil penelitian lain, menunjukan bahwa sebanyak 50\% dari pengunjung klinik aborsi berusia 15-20 tahun, dan 44,5\% dari pengunjung klinik aborsi berusia antara 15-20 tahun itu adalah hamil di luar nikah (Meggit, 2013). Fenomena perilaku seks pra nikah ini tidak hanya terjadi di Jakarta. Sebuah penelitian terhadap 37 remaja berusia 16-20 tahun di Jatinangor, Kabupaten Sumedang, Provinsi Jawa Barat pada tahun 1998, menunjukkan bahwa sekitar $80 \%$ telah melakukan perilaku sexual necking; 70\% pernah melakukan petting; dan 65\% pernah melakukan premarital intercourse (Phillips, 2008).

Pemberitaan di televisi pun menyuguhkan tayangan tentang tindakan amoral siswa, seperti vandalism oleh siswa, pemerkosaan yang korban dan pelakunya siswa sekolah, pencurian, perampokan,geng motor yang berakhir dengan perkelahian dengan senjata tajam.
Belum lagi kasus video porno yang ternyata $90 \%$ pelaku dan pembuatnya adalah siswa remaja (Mahmudi, 2013) seperti yang diungkapkan oleh Mutia Hatta yang dilansir dalam Media Indonesia bahwa "Saat ini ada lebih dari 500 jenis video porno yang telah beredar, yang 90\% dibuat dan dilakukan oleh remaja Indonesia yang masih berstatus pelajar (Menteri Pendidikan Nasional, 2010).

Berdasarkan hasil penelitian Synovate Research tentang perilaku seksual remaja di 4 kota dengan 450 responden, yaitu Jakarta, Bandung, Surabaya dan Medan, 44\% responden mengaku mereka sudah pernah punya pengalaman seks di usia 16 sampai 18 tahun. Sementara 16\% lainnya mengaku pengalaman seks itu sudah mereka dapat antara usia 13 sampai 15 tahun (Safitri, 2015). Kasus Narkoba di Indonesia berdasarkan laporan Badan Nasional Anti Narkoba, pada tahun 2007 ditemui sekitar 22.630 kasus. Di Jawa Barat sendiri, kasus narkoba masuk sebagai peringkat ke IV dengan 1.086 kasus (Kristiawan, 2015).

Masalah lain, bullying, semakin marak terjadi dalam setiap aktivitas anak di sekolah. Berdasarkan penelitian yang dilakukan Komisi Nasional Perlindungan Anak tahun 2007 lebih dari 90\% anak pernah diejek di sekolah. Selain itu, penelitian yang didukung oleh Badan Perserikatan Bangsa-Bangsa (PBB) untuk Masalah Anak (UNICEF), masih banyak anak-anak di Indonesia yang mendapatkan perlakuan buruk dari temannya sendiri. Survei yang dilakukan pada 2002 melibatkan 125 anak dan berlangsung selama enam bulan. Survei itu meliputi wawancara yang diawasi dengan sangat teliti. Dari survei itu terungkap, dua per tiga anak laki-laki dan sepertiga anak perempuan pernah dipukul. Lebih dari seperempat anak perempuan dalam survei itu mengalami perkosaan.

Sementara itu, berdasarkan penelitian Departemen Kesehatan Republik Indonesia terhadap pada siswa di 18 
provinsi, terdapat satu dari enam siswa mengalami tindakan kekerasan di sekolah dengan cara melukai, memberikan ancaman, menciptakan teror, dan menunjukkan sikap permusuhan sehingga menimbulkan dampak seperti stress (76\%), hilang konsentrasi $(71 \%)$, gangguan tidur $(71 \%)$, paranoid (60\%), sakit kepala (55\%), dan obsesi (52\%). Sedikitnya $25 \%$ anak yang diganggu memilih menghabisi nyawanya sendiri dengan jalan bunuh diri.

Tindakan kekerasan juga berdampak pada para pelaku yaitu mereka merasa menjadi jagoan sehingga senang berkelahi $(54 \%)$, berbohong $(87 \%)$, serta tidak memperdulikan peraturan sekolah (33\%). Tindakan kekerasan di jalur pendidikan formal juga memberi dampak pada kehidupan sosial. Berdasarkan penelitian Marjohan (2014) menunjukkan, terdapat 67 orang remaja terisolir dari keseluruhan 294 remaja. Penelitian Maunah (2015) menyatakan ada $14.14 \%$ remaja terisolir, maknanya dari setiap seratus orang remaja, sebanyak 14 orang terisolir. Penelitian Kristiawan (2016) menyatakan, dari 278 orang remaja, terdapat $12.9 \%$ atau 36 orang remaja yang terisolir. Hasil tersebut sejalan dengan hasil penelitian di SMP Negeri 3 Bandung, terdapat 10 orang $(13.89 \%)$ remaja terisolir dari 72 orang remaja. Data-data tersebut bermakna bahwa di setiap sekolah terdapat anak-anak yang secara teori mengalami gangguan dalam proses sosialisasi akibat statusnya sebagai remaja terisolir.

Banyak pihak yang menanggapi fenomena diatas. Kritik terhadap sistem pendidikan dan pembelajaranpun dilayangkan. Pendidikan kita dinilai terlalu menonjolkan sisi kognisi tetapi minus emosi dan moral. Sebagian bahkan menilai pendidian Indonesia terkesan mekanistik, full hafalan dan mematikan kreativitas siswa. Kondisi ini tentumencemaskan berbagai fihak, apalagi melihat dari pendapat Lickona (1994) bahwa terdapat sepuluh tanda perilaku manusia yang menunjukkan arah kehancuran suatu bangsa,yaitu (1) meningkatnya kekerasan di kalangan remaja; (2) ketidakjujuran yang membudaya; (3) semakin tingginya rasa tidak hormat kepada orang tua, guru dan figure pemimpin; (4) pengaruh peer group terhadap tindakan kekerasan; (5) meningkatnya kecurigaan dankebencian; (6) penggunaan bahasa yang buruk; (7) penurunan etos kerja; (8) menurunnya rasa tanggungjawab individu dan warga Negara; (9) meningkatnya perilaku merusak diri; (10) semakin kaburnya pedoman moral.

Dari berbagai fakta tersebut menunjukan masih banyak penyimpangan karakter yang terjadi. Padahal menurut Dalam Peraturan Presiden Nomor 87 Tahun 2017 tentang Penguatan Pendidikan Karakter dalam Pasal 3 disebutkan bahwa: "PPK dilaksanakan dengan menerapkan nilai-nilai Pancasila dalam pendidikan karakter terutama meiliputi nilai-nilai religius, jujur, toleran, disiplin, bekerja keras, kreatit mandiri, demokratis, rasa ingin tahu, semangat kebangsaan, cinta tanah air, menghargai prestasi, komunikatif, cinta damai, gemar membaca, peduli lingkungan, peduli sosial, dan bertanggungjawab."

Berdasarkan Peraturan Presiden Nomor 87 Tahun 2017 tersebut menyatakan bahwa pendidikan berfungsi untuk membentuk watak. Watak inilah yang disebut sebagai karakter. Pendidikan karakter memiliki peran penting dalampembentukan moral. Karakter berkaitan dengan konsep moral, sikap moral, dan perilaku moral. Berdasarkan tiga komponen tersebut maka dapat disimpulkan bahwa karakter yang baik didukung oleh pengetahuan tentang kebaikan, keinginan untuk berbuat baik, serta melakukan perbuatan yang baik (Budimansyah, 2010).

Penguatan Pendidikan Karakter merupakan kelanjutan dan revitalisasi gerakan nasional pendidikan karakter yang telah dimulai pada 2010. Penguatan pendidikan karakter (character education) atau pendidikan moral 
(moral education) dalam masa ini perlu diimplementasikan untuk mengatasi krisis moral yang sedang melanda negeri ini. Hadirnya penguatan pendidikan karakter memiliki peran yang sangat penting, karena perubahan perilaku peserta didik (sebagai hasil dari proses pendidikan karakter) sangat ditentukan oleh faktor lingkungan. Dengan kata lain, pembentukan dan lingkungan yang mencakup diantaranya lingkungan fisik dan budaya sekolah, manajemen sekolah, kurikulum, pendidik, dan metode mengajar.

Pembentukan karakter melalui faktor lingkungan dapat dilakukan melalui beberapa strategi, antara lain yaitu keteladanan, intervensi, pembiasaan yang dilakukan secara konsisten dan penguatan. Dengan kata lain, perkembangan dalam pembentukan karakter memerlukan keteladanan yang ditularkan, intervensi melalui proses pembelajaran, pelatihan, pembiasaan terus-menerus dalam jangka panjang yang dilakukan secara kontinyu dan penguatan, serta harus diimbangi dengan nilai-nilai luhur. Hal tersebut sesuai dengan prinsip PPK dalam Peraturan Presiden Republik Indonesia Nomor 87 Tahun 2017 tentang Penguatan Pendidikan Karakter pasal 5 yang berbunyi: (a) berorientasi pada berkembangnya potensi peserta didik secara menyeluruh dan terpadu, (b) keteladanan dalam penerapan pendidikan karakter pada masing-masing lingkungan pendidikan, dan (c) berlangsung melalui pembiasaan dan sepanjang waktu dalam kehidupan sehari-hari. Pemerhati dan pelaku pendidikan telah mencoba membenahi sistem pendidikan dan kurikulum dengan menawarkan berbagai solusi. Salah satunya dengan mengoptimalkan layanan dalam Bimbingan dan Konseling.

Bimbingan dan konseling di sekolah diselenggarakan untuk memfasilitasi perkembangan peserta didik/konseli agar mampu mengaktualisasikan potensi dirinya dalam rangka mencapai perkembangan secara optimal. Fasilitasi dimaksudkan sebagai upaya memperlancar proses, karena secara kodrati setiap manusia berpotensi untuk berkembang. Bimbingan dan konseling saat ini merupakan upaya pengembangan potensi-potensi positif individu. Semua peserta didik berhak mendapatkan layanan bimbingan dan konseling agar potensi-potensi positif yang mereka miliki berkembang optimal. Pengembangan potensipotensi positif memungkinkan individu mencapai aktualisasi diri. Meskipun demikian, paradigma bimbingan dan konseling ini tidak mengabaikan layanan-layanan yang berorientasi pada pencegahan (Upaya mewujudkan potensi peserta didik/konseli menjadi kompetensi dan prestasi hidup memerlukan sistem layanan pendidikan integratif. Kompetensi hidup dikembangkan secara isimengisi atau komplementer antara guru bimbingan dan konseling atau konselor dengan guru mata pelajaran dalam satuan pendidikan.

Esensi bimbingan dan konseling tertuang dalam definisinya yang termuat pada Peraturan Menteri Pendidikan dan Kebudayaan Republik Indonesia (Permendikbud RI) No. 111 Tahun 2014 mengartikan bimbingan dan konseling dipandang sebagai upaya sistematis, objektif, logis, dan berkelanjutan serta terprogram yang dilakukan oleh konselor atau guru bimbingan dan konseling untuk memfasilitasi perkembangan peserta didik/konseli untuk mencapai kemandirian dalam kehidupannya. Realisasi bimbingan dan konseling melahirkan program dan sejumlah bentuk pelayanan yang dilakukan oleh konselor atau guru bimbingan dan konseling. Layanan yang dimaksud diantaranya adalah layanan yang bersifat konseling maupun bimbingan baik dalam bentuk individual ataupun kelompok. 


\section{METODOLOGI}

Lokasi pelaksanaan workshop mengambil tempat gedung pancasila kota tanjung kabupaten tabalong. Waktu pelaksanaan dilakukan sehari yakni pada tanggal 26 Agustus 2019, dengan agenda kegiatan seperti yang tertera pada Tabel I.

Tabel I. Agenda Kegiatan

\begin{tabular}{|c|c|}
\hline Waktu Pelaksanan (WITA) & Agenda Kegiatan \\
\hline $09.00-09.30$ & Registrasi Peserta \\
\hline \multirow[t]{6}{*}{ 09.30-10.00 } & Pembukaan \\
\hline & Kata Sambutan \\
\hline & Foto Bersama \\
\hline & Penyerahan sertifikat \\
\hline & Doa \\
\hline & Penutup \\
\hline \multirow[t]{2}{*}{$10.00-11.00$} & Memahami Penguatan \\
\hline & Pendidikan Karakter \\
\hline $11.00-12.00$ & $\begin{array}{l}\text { Perencanaan Program PPK } \\
\text { dalam Bimbingan } \\
\text { Konseling }\end{array}$ \\
\hline $12.00-13.00$ & Ishoma \\
\hline \multirow[t]{2}{*}{$13.00-14.00$} & praktikum PPK dalam \\
\hline & Bimbingan dan Konseling \\
\hline $14.00-15.00$ & $\begin{array}{l}\text { Evaluasi, Pelaporan dan } \\
\text { Tindak Lanjut }\end{array}$ \\
\hline $15.00-15.30$ & Penutup \\
\hline
\end{tabular}

Latar belakang peserta workshop berasal dari guru SMP Sederajat Se-Kabupaten Tabalong Provinsi Kalimantan Selatan dengan kategorisasi praktis adalah guru bimbingan dan konseling dari berbagai jenjang sekolah menengah Peratama dan pengawas bimbingan dan konseling dari dinas pendidikan, seperti tertera pada Tabel II.

Tabel II. Latar Belakang Peserta Sosialisasi

\begin{tabular}{lll}
\hline No. & Kategori Peserta & Jumlah \\
\hline 1. & Guru BK di Sekolah & 37 orang \\
2. & Pengawas BK & 1 orang \\
\hline Jumlah Keseluruhan & 37 orang \\
\hline
\end{tabular}

Metode kegiatan adalah peningkatan pemahaman terhadap suatu masalah, yang dibingkai dalam bentuk kegiatan workshop atau proses pemahaman pelaksanaan layanan bimbingan dan konseling dalam penguatan pendidikan karakter yang berbasis pada panduan operasional penyelenggaraan bimbingan dan konseling yang telah dikeluarkan Kementerian Pendidikan dan Kebudayaan pada tahun 2016. Secara teknis penyelenggaraan workshop ini dilakukan dengan teknik ceramah, sharing pengalaman tanya jawab dan praktikum.

\section{HASIL DAN PEMBAHASAN}

Secara umum pelaksanaan workshop berlangsung dalam beberapa tahapan kegiatan yakni: registrasi, ceramah, sharing pengalaman, tanya-jawab dan praktikum. Perlu dikemukakan bahwa pada tahap ceramah dan sharing pengalaman dilakukan oleh seorang narasumber yaitu Akhmad Sugianto, dosen dari Program Studi Bimbingan dan Konseling Universitas Lambung Mangkurat.

Secara keseluruhan, berikut ini diuraikan tahap kegiatan pengabdian yang dilakukan.

1. Registrasi, Registrasi peserta sosialisasi dilakukan satu minggu sebelum hari pelaksanaan melalui koordinator guru MGBK yakni dari 17 Agustus sampai pada 25 Agustus 2019. Selama proses registrasi ini didapat kesediaan 37 orang yang bersedia menjadi peserta.

2. Ceramah, Tahapan ceramah dimaksudkan menyampaikan materi kegiatan pengabdian kepada masyarakat. Pembagian materi ceramah didasarkan pada buku yang dikeluarkan Kementerian Pendidikan dan Kebudayaan pada tahun 2016 yang berjudul: Pedoman Bimbingan dan Konseling pada Pendidikan Dasar dan Pendidikan Menengah. Materi yang disampaikan berkaitan penguatan pendidikan karakater melalui layanan bimbingan dan konseling, yang disampaikan oleh Akhmad Sugianto dari Program Studi Bimbingan dan Konseling Universitas Lambung Mangkurat.

3. Sharing Pengalaman, Sharing pengalaman adalah kegiatan berbagi pengalaman mengimplementasikan layanan bimbingan dan konseling berbasis panduan operasional 
penyelenggaraan bimbingan dan konseling yang telah dilakukan oleh guru bimbingan dan konseling. Adapun materi yang disampaikan berdasarkan pada Panduan Operasional Penyelenggaraan Bimbingan dan Konseling: Sekolah Menengah Pertama (SMP). Isi materi yang disampaikan adalah lingkup layanan bimbingan dan konseling untuk penguatan pendidikan karakter.

4. Tanya-jawab, Dalam pelaksanaan tahap tanya-jawab peserta workshop diberi kesempatan untuk bertanya tentang materi materi workshop dan mengisahkan pengalamannya selama melaksanakan layanan bimbingan dan konseling di sekolah. Pada sesi tanya jawab ini ditemukan sejumlah hal yang dikemukakan oleh peserta workshop diantaranya: (1) peserta workshop kurang begitu memahami implementasi layanan bimbingan dan konseling dalam penguatan pendidikan karakter berbasis panduan operasional penyelenggaraan bimbingan dan konseling karena merasa terbiasa melakukan layanan berpatokan pada pelayanan bimbingan dan konseling kurikulum lama; (2) peserta workshop dari guru bimbingan dan konseling juga menyatakan bahwa selama proses layanan bimbingan dan konseling berlangsung mereka lebih mengandalkan intuisi pada pengalaman mereka selama menjadi guru bimbingan dan konseling; dan (3) akan tetapi peserta workshop juga menyambut baik adanya kegiatan workshop implementasi layanan bimbingan dan konseling dalam penguatan pendidikan karakter berbasis panduan operasional penyelenggaraan bimbingan dan konseling sebab terkait dengan perkembangan peserta didik sekarang yang lebih kritis dan tuntutan Kementerian Pendidikan dan Kebudayaan akan profesional profesi bimbingan dan konseling dalam menangani peserta didik.

\section{KESIMPULAN}

Pelaksanaan workshop berjalan dengan baik, meski Beberapa peserta kurang memahami bagaimana implementasi layanan bimbingan dan konseling dalam penguatan karakter. Peserta workshop juga menyatakan bahwa mereka lebih mengandalkan intuisi dan pengalaman, namun mereka menyambut baik pelaksanaan workshop tersebut.

\section{UCAPAN TERIMA KASIH}

Kegiatan pengabdian dapat berjalan dengan lancer berkat adanya dukungan dari berbagai pihak. Saya ucapkan terima kasih kepada Musyawarah Guru Bimbingan dan Konseling Kabupaten Tabalong yang sudah memfasilitasi untuk kegiatan ini. saya ucapkan juga kepada FKIP ULM yang berkenan mendukung kegiatan ini secara moril sehingga kegiatan ini dapat terlaksana. serta tidak lupa kepada peserta pengabdian yang sudah berkenan mengikuti kegiatan ini dari awal sampai akhir secara konsisten.

\section{REFERENSI}

Budimansyah, D. 2010. Penguatan Pendidikan Kewarganegaraan Untuk Membangun Karakter Bangsa. Bandung: Widya Aksara Press

Jalal. F. 2010. Kebijakan Nasional Pendidikan Karakter: Tiga Stream Pendekatan. Jakarta: Kementerian Pendidikan Nasional

Kristiawan, M. 2016. Telaah Revolusi Mental Dan Pendidikan Karakter Dalam Pembentukkan Sumber Daya Manusia Indonesia Yang Pandai Dan Berakhlak Mulia. Ta'dib. 18(1):1325. http://dx.doi.org/10.31958/jt.v18i1.274

Kristiawan, M. 2015. A Model of Educational Character in High School Al-Istiqamah Simpang Empat, West Pasaman, West Sumatera. Research Journal of Education. 1(2):15-20. 
Lickona, T. 1994. Raising Good Children: Helping Your Child Through the Stage of Moral Development. New York: Bantam Books

Mahmudi, I. 2013. Pembentukan Karakter Melalui Layanan Bimbingan Dan Konseling Islami. COUNSELLIA: Jurnal Bimbingan dan Konseling. 3(1):1-15.

http://doi.org/10.25273/counsellia.v3i1.238

Marjohan. 2014. Hubungan Keteladanan Orang Tua terhadap Perilaku Sosial Siswa. Jurnal Ilmiah PPKn IKIP Veteran Semarang. 2(1):14-23.

Maunah, B. 2015. Implementasi Pendidikan Karakter Dalam Pembentukan Kepribadian Holistik Siswa. Jurnal Pendidikan Karakter. 5(1):90-101. https://doi.org/10.21831/jpk.v0i1.8615

Meggit, C. 2013. Memahami Perkembangan Anak. Jakarta: PT Indeks

Menteri Pendidikan Nasional. 2010. Penerapan Pendidikan Karakter Dimulai di SD. https://www.antaranews.com/berita/18692 8/mendiknas-penerapan-pendidikankarakter-dimulai-sd

Phillips, S. 2008. Refleksi Karakter Bunga Bangsa. Jakarta: Bumi Aksara

Pratama, E.D. 2018. Pelaksanaan Penguatan Pendidikan Karakter Di SMK Negeri 2 Pengasih. Jurnal Pendidikan Vokasi Otomotif. 23(1):11-26.

Safitri, N.M. 2015. Implementasi Pendidikan Karakter Melalui Kultur Sekolah Di SMP N 14 Yogyakarta. Jurnal Pendidikan Karakter. 5(2):173-183.

https://doi.org/10.21831/jpk.v0i2.8621

Susilo, A., Sarkowi, S. 2018. Peran Guru Sejarah Abad 21 dalam Menghadapi Tantangan Arus Globalisasi. Historia: Jurnal Pendidik dan Peneliti Sejarah.

2(1):43-50. https://doi.org/10.17509/historia.v2i1.11206 